\title{
Design and Heat Load Analysis of a 12 MW HTS Wind Power Generator Module Employing a Brushless HTS Exciter
}

\author{
H. J. Sung, R. A. Badcock, Z. Jiang, J. Choi, M. Park, and I. K. Yu
}

\begin{abstract}
Brushless HTS flux pump exciters, which enable large currents to be injected into a superconducting circuit without requiring a power supply, slip ring, and current leads, are promising candidates for HTS rotating machine application.

This paper outlines the design and heat load analysis of a 12 MW HTS wind power generator module employing a brushless HTS exciter. The 12 MW HTS generator module and the HTS exciter were simulated using the 3D finite element method. The module design of the generator was focused on reducing the heat load and inductance per rotor pole for application of an HTS exciter. A highly permeable ferromagnetic material was used to increase the magnetic flux density incident on the HTS stator wire of the exciter, even with a large radial gap between the rotor and the stator, and hence increase the injected current. Based on the electromagnetic simulations, the design of the module was confirmed, and the iron loss of the exciter was calculated. And then the conduction and radiation heat loads were simulated. The induced DC current value and ramping time of the DC current at the HTS stator wire of the exciter were calculated. The detailed results of the module with the HTS exciter were discussed, and the results obtained in the study are useful in designing largescale HTS generators.
\end{abstract}

Index Terms - Generators, High-temperature superconductors, Rotating machines, Wind energy.

\section{INTRODUCTION}

$\mathrm{H}_{1}$ IGH TEMPERATURE Superconducting (HTS) generators have the potential for significant reductions in volume and weight and an increased power density for large-scale wind power systems. Many researchers have aimed to develop a feasible HTS generator technology [1]-[4].

A large scale HTS generator has a huge vacuum vessel, and it is difficult to repair and maintain the HTS field coils. In particular, all of the HTS field coils are normally connected in a series, and thus, if one HTS coil fails, the other coils break down through a domino effect. Modularization of the

This work was supported by the Power Generation \& Electricity Delivery Core Technology Program of the Korea Institute of Energy Technology Evaluation and Planning (KETEP), granted financial resource from the Ministry of Trade, Industry \& Energy, Republic of Korea. (No. 20142020103560). (Corresponding author: I. K. Yu)

H. J. Sung, J. Choi, M. Park, and I. K. Yu are with the Electrical Engineering Department, Changwon National University, Changwon-si, Rep. of Korea (e-mail: yuik@ cwnu.ac.kr).

R. A. Badcock and Z. Jiang are with Robinson Research Institute, Victoria University of Wellington, PO Box 33436, New Zealand (e-mail: rod.badcock@vuw.ac.nz) generators can solve the problem because each pole is structurally separated.

Conventional leads require a power supply and slip rings for transferring the DC current into HTS field coils. The slip rings demand regular maintenance, and current leads that bridge between the cryogenic environment and room temperature pose a substantial heat load on the cryogenic cooling system due to a combination of electrical resistance and heat conduction. The brushless HTS exciter is able to inject DC current into a superconducting circuit without current leads which means it can reduce the heat load of the generator [5][8].

In this paper, a 12 MW HTS wind power generator module employing a brushless HTS flux pump exciter was designed, and the heat load of the module was analysed. A zigzaghoneycomb type structure was introduced in the module to support the HTS field coil and reduce the conduction heat load.

The module design focuses on lowering the heat load using the HTS coil supporter and the inductance of the HTS field coil, which affects the charging and discharging time of the injected DC current for coil excitation. The temperature and the magnetic field distributions of the module were analysed using the 3D Finite Elements Method (FEM).

Based on the design results of the integrated exciter module, the pumped DC current value and the charging and discharging time of the HTS field coil were calculated. To achieve the field current rated value and reduce ramping time of the current, the HTS stator wires in the exciter were connected in parallel and series. The iron-loss and Joule loss of the HTS exciter in the module was obtained through the processes mentioned above. Finally, the heat load of the module was estimated, and the design specifications of the module were proposed. These results will be applied to largescale HTS rotating machines with brushless HTS exciters.

\section{Configuration of a 12 MW HTS Generator Module WITH A BRUSHLESS HTS EXCITER}

The integrated exciter HTS generator module consists of a cryostat, HTS field coils of one pole, coil bobbins, bobbin supporters, a coil supporter, a heat transfer structure, and lower parts of the exciter, as shown in Fig. 1. The modules are not electrically connected and are structurally separated. Therefore, it facilitates a lower cryogenic volume, as well as easier repair, assembly, and maintenance of the HTS field coil. It is a promising candidate for large-scale HTS generators and 
helps to improve the possibility of commercial mass production.

\section{FIG. 1 HERE}

The material of the heat transfer structure is copper, which is directly connected to the cold head of the cryocooler. In addition, the coil bobbin uses aluminium to support the HTS wires and transfer heat between the copper and HTS coils. The material of the cryostat and bobbin supporter is stainless steel. The coil supporter is made of fibre-reinforced plastic to improve heat insulation between the cryostat and the HTS coils.

\section{A. Design of the HTS Field Coils}

To design the HTS field coils, basic properties of the 12 MW HTS generator are determined. The rotational speed and the line-to-line output voltage of the generator are $8 \mathrm{rpm}$ and $6.6 \mathrm{kV}$, respectively. The output torque of the generator is 14.7 MN.m and the air-gap between the rotor part and stator part is $30 \mathrm{~mm}$. In the stator, the current density of the stator copper coil is $3 \mathrm{~A} / \mathrm{mm}^{2}$ considering forced air-cooling and water-cooling methods. There are 15 turns and 2 solts/poles/phases with a short pitch distributed winding method.

In the rotor, the width and thickness with insulation of the HTS wire are $12 \mathrm{~mm}$ and $0.125 \mathrm{~mm}$ [9]. The number of rotor poles is 30 . The operating temperature of the rotor is $20 \mathrm{~K}$, the ratio of the operating current over the coil critical current of $506 \mathrm{~A}$ is $70 \%$. Each pole consists of 400 HTS turns per coil and 3 double pancake coil layers. The effective length of the HTS coils is $450 \mathrm{~mm}$. The calculated inductance and length of the HTS wire per pole are $4.84 \mathrm{H}$ and $4.35 \mathrm{~km}$, respectively.

\section{B. Design of the Brushless HTS Exciter}

The brushless HTS flux pump exciter can be divided into part of rotor and stator components. The permanent magnets are located at the rotor which is rotated past the interlocking stator teeth of the generator.

In the module, the stator part of the exciter is situated close to the rotor coil in order to maintain connection of the HTS stator wire to HTS field coils. The DC current in the HTS stator wire is excited by a rotating magnetic field of the permanent magnets with a quasi-DC electro motive force [5]. The exciter for the $12 \mathrm{MW}$ HTS generator is already designed in ref. [11]. The number of permanent magnets is 11, and the diameter of the exciter is $200 \mathrm{~mm}$. The length of the module is determined while considering the stator part size of the exciter. The configuration of the exciter in the module is shown in Fig. 2.

\section{FIG. 2 HERE}

\section{Simulation Results AND Discussions}

\section{A. Analysis of Electromagnetic Characteristics}

The module of the 12 MW HTS generator is simulated using 3D FEM program. The electromagnetic characteristics of the module are analysed to estimate the perpendicular magnetic field to the wide tape surface and the eddy current losses of the structures in the module. Fig. 3 shows the magnetic field distribution of the module with the stator of the generator.

\section{FIG. 3 HERE}

The perpendicular and maximum magnetic flux densities of the module are $5.4 \mathrm{~T}$ and $7.2 \mathrm{~T}$, respectively. Therefore, an excitation current of $352 \mathrm{~A}$ is required to energize the HTS field coils. The magnetic flux density of the air-gap between the rotor part and stator part of the generator is $2.5 \mathrm{~T}$. The stator teeth core uses magnetic material (or iron-core) to improve magnetic flux density and the electro-motive force in the stator copper coils. The magnetic material also acts to reduce the total length of the HTS wire. The material of the core is silicon-laminated steel to decrease iron loss. The magnetic flux density at the inside point of the stator teeth is 3.4 T, which means the iron-core is saturated. However, at the outside point of the stator teeth, the density is not saturated at $0.16 \mathrm{~T}$, which can help the magnetic flux flow along the core. The eddy current loss of the cryostat of the module is $125 \mathrm{~W}$.

The magnetic field results of the HTS exciter can be found in ref. [10]. Based on the results, the charging and discharging time of the injected DC current for the module of the $12 \mathrm{MW}$ HTS generator are calculated. The DC voltage for a HTS stator wire is $1.16 \mathrm{mV}$. The dynamic resistance, which is verified in a type-II superconductor with a time-varying magnetic field, is calculated by $7.25 \mu \Omega$ with $122 \mathrm{rpm}$. The total joint resistance of the exciter is $3 \mu \Omega$. The single HTS wire can induce the DC current to 113 A. Four parallel connections and five series connections of the HTS stator wires are used to achieve the field current $(352 \mathrm{~A})$ in the module. As a result, the total resistance of the exciter is $79 \mu \Omega$, and the charging and discharging times of the pumping current in the exciter are 1.6 days and 2 days, respectively.

From the HTS exciter, the heat load including iron loss and Joule loss can be estimated. The iron loss of the exciter is 0.2 $\mathrm{W}$ in which hysteresis loss and eddy current loss are calculated. Joule loss of the exciter is $10 \mathrm{~W}$ based on the based on the sum of the resistances.

\section{B. Analysis of Heat Load Characteristics}

To analyse the heat load of the module for the HTS generator, there are five major heat sources:

1. Excitation: in this paper, the brushless HTS exciter is considered. Therefore, it has iron loss at the stator part and joule loss by the dynamic and joint resistances.

2. Conduction through cryostat and support structures: the conduction loss through the structures in the module can be calculated using the Fourier heat law with the 3D FEM program.

3. Radiation: the radiative heat in the module is evaluated by the Stefan-Boltzmann equation with the 3D FEM program. 
4. Eddy current: the eddy current losses of the cryostat and bobbin structures in the module occur by stator AC current and the stator core.

5. HTS field coil: AC loss of the HTS field coils should be calculated. However, in this paper, the bobbin structures act as electro-magnetic shield to provide shielding of the harmonic fields from the stator winding and core. Therefore, it reduces the AC loss in the HTS field coil [2].

In the previous section, the excitation heat load is calculated as $10.2 \mathrm{~W}$. The eddy current loss of the cryostat of the module is $125 \mathrm{~W}$ which does not effect to the cooling capacity in a vacuum. The materials of other structures are considered to be laminated. Therefore, the eddy current losses of the structures are ignored in the module.

The conduction heat load is the key factor for cooling the module. To reduce the heat load, a design of the coil supporter located between HTS coils and cryostat is important. Fig. 4 shows the configuration and the heat distribution of the zigzag-honeycomb type coil supporter.

\section{FIG. 4 HERE}

The zigzag type is applied to increase the length of heat transfer path, and the honeycomb shape is adopted at the first layer of the zigzag type to reduce the contact area. In this supporter, the length of heat transfer path and the contact area of the coil supporter are $0.093 \mathrm{~m}^{2}$ and $1.77 \mathrm{~m}$, respectively. The conduction heat load of the module is $5.5 \mathrm{~W}$. The temperature of the top of the supporter contacted with HTS coil is $14.9 \mathrm{~K}$. The radiation heat load of the module is $3.9 \mathrm{~W}$ in which the radiation area is $1.15 \mathrm{~m}^{2}$.

The heat budgets of the module are described in Table I. Therefore, the total heat load including excitation, conduction, and radiation heat loads is $19.6 \mathrm{~W}$.

\section{TABLE I HERE}

When a 1-stage Gifford-McMahon (SRDK-500B) cryocooler system is applied [11], it has a sufficient cooling capacity to cool the HTS coils in the module down to $13.7 \mathrm{~K}$. It is suitable to the operating temperature of the generator. Fig. 5 illustrates the heat distribution of the HTS coils in the module.

\section{FIG. 5 HERE}

\section{CONCLUSIONS}

In this paper, a 12 MW HTS wind power generator module employing a brushless HTS exciter was designed, and the heat load of the module was analysed. As a result, the volume of the module was $0.17 \mathrm{~m}^{3}$, and the operating DC field current was $354 \mathrm{~A}$ for the $12 \mathrm{MW}$ generator. The calculated inductance and length of the HTS wire per pole were $4.84 \mathrm{H}$ and $4.35 \mathrm{~km}$, respectively. The charging and discharging times of the pumping current in the HTS exciter were 1.6 days and 2 days, respectively. Based on the electromagnetic results, the eddy current loss of the cryostat of the module was $125 \mathrm{~W}$ which does not effect to the cooling capacity in a vacuum. The heat load of the HTS exciter in the module was $10.2 \mathrm{~W}$.

The conduction heat load of the module was $5.5 \mathrm{~W}$. The temperature of the top of the supporter contacted with HTS coil was $14.9 \mathrm{~K}$. The radiation heat load of the module was 3.9 $\mathrm{W}$ in which the radiation area $1.15 \mathrm{~m}^{2}$. Therefore, the total heat load including excitation, conduction, and radiation heat loads was $19.6 \mathrm{~W}$. The 1-stage cryocooler has a sufficient cooling capacity to cool the HTS coils in the module down to $13.7 \mathrm{~K}$.

In the next step of the research, the AC loss of the HTS field coils will be analysed in detail. The results obtained through the study will be utilized to design large-scale HTS generators.

\section{REFERENCES}

[1] H. J. Sung, G. H. Kim, K. Kim, S. J. Jung, M. Park, I. K. Yu, Y. G. Kim, H. Lee, and A. R. Kim, "Practical design of a 10 MW superconducting wind power generator considering weight issue," IEEE Trans. Appl. Supercond., vol. 23, no. 3, Jun. 2013, Art. ID. 5201805.

[2] H. Karmaker, M. Ho, E. Chen, and D. Kulkarni, "Direct drive HTS wind generator design for commercial applications," Electrical Machines., 2014, pp. 491-495.

[3] HORIZON 2020, Thyborøn, Denmark. EcoSwing-World's First Demonstration of a 3.6 MW Low-Cost Lightweight DD Superconducting Generator on a Wind Turbine. (2015) [Online]. Available: http://cordis.europa.eu/project/rcn/195203_en.html, Accessed on 01 Mar. 2015.

[4] H. J. Sung, G. H. Kim, K. Kim, M. Park, I. K. Yu, and J. Y. Kim, "Design and comparative analysis of $10 \mathrm{MW}$ class superconducting wind power generators according to different types of superconducting wires," Physica C., vol. 494, pp. 255-261, Nov. 2013.

[5] Z. Jiang, K. Hamilton, N. Amemiya, R. A. Badcock, and C. W. Bumby, "Dynamic resistance of a high-Tc superconducting flux pump," Applied Physics Letters., vol. 105, no. 11, Sep. 2014, Art. ID. 112601.

[6] Z. Jiang, C. W. Bumby, R. A. Badcock, H. J. Sung, N. J. Long, and N. Amemiya, "Impact of flux gap upon dynamic resistance of a rotating HTS flux pump," Supercond. Sci. and Techno., vol. 28, no. 11, Sep. 2015, Art. ID. 115008.

[7] C. Hoffmann, D. Pooke, A.D. Caplin, "Flux pump for HTS magnets," IEEE Trans. Appl. Supercond., vol. 21, no. 3, pp. 1628-1631, Jun. 2011.

[8] C.W. Bumby, R.A. Badcock, H-J. Sung, K-M. Kim, Z. Jiang, A.E. Pantoja, P. Bernardo, M. Park, R.G. Buckley, "Development of a brushless HTS exciter for a $10 \mathrm{~kW}$ HTS synchronous generator," Supercond. Sci. Technol., submitted for publication.

[9] SuperPower Inc., Schenectady, NY, USA. SuperPower 2G HTS wire specifications. (2014) [Online]. Available: http://www.superpowerinc.com/system/files/SP_2G+Wire+Spec+Sheet_2014_web_v1_0.pdf.

[10] H. J. Sung, R. A. Badcock, B. S. Go, M. Park, I. K. Yu, and Z. Jiang, "Design of a 12 MW HTS Wind Power Generator using a Flux Pump Exciter," IEEE Trans. Appl. Supercond. Submitted for publication.

[11] Sumitomo Heavy Industries Cryogenics Group, Tokyo, Japan. SRDK500B 20K cryocooler series specifications. [Online]. Available: http://www.shicryogenics.com/wp-content/uploads/2015/09/RDK-500BDatasheet.pdf. 


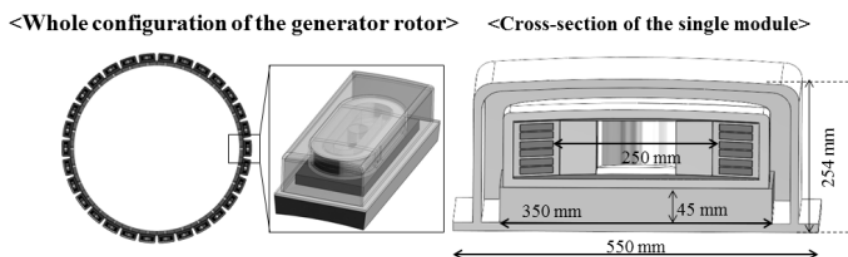

$<$ A side view of the single module $>$

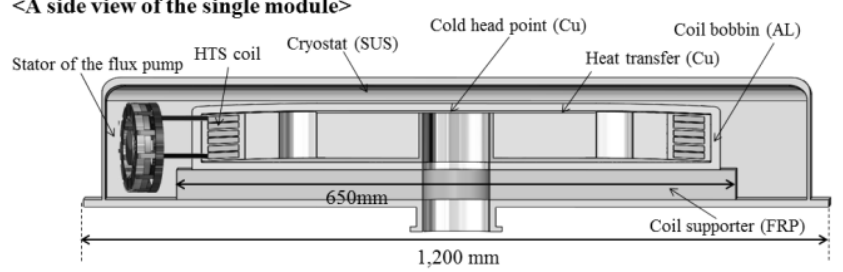

Fig. 1. Configuration of the $12 \mathrm{MW}$ HTS generator module. The dimensions and materials of each part are illustrated in detail.

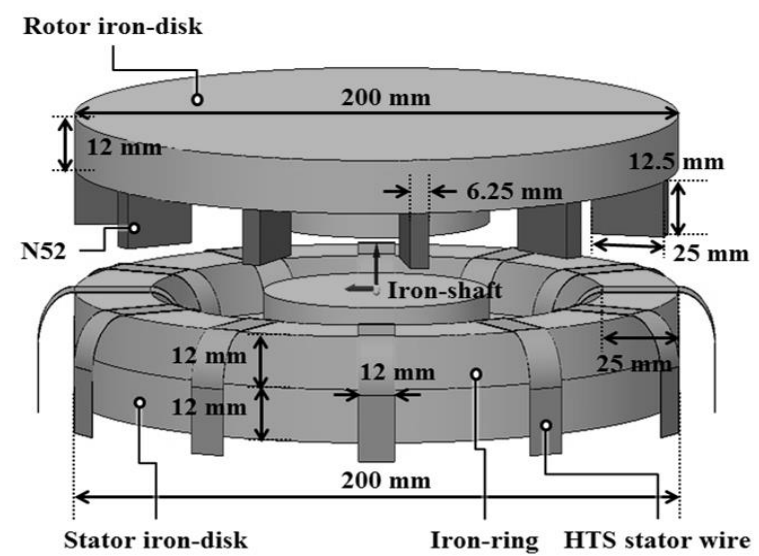

Fig. 2. Configuration of the brushless HTS exciter in the module [11].

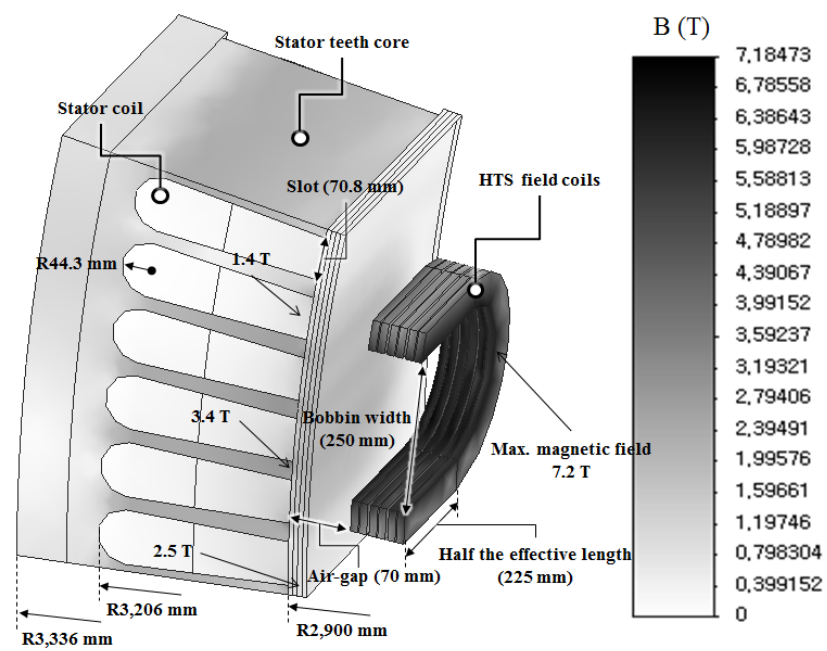

Fig. 3. Magnetic field distribution of $1 / 60$ simulation model of the module with the stator part in the generator. The odd-periodic boundary with half the effective length was adopted in the model.

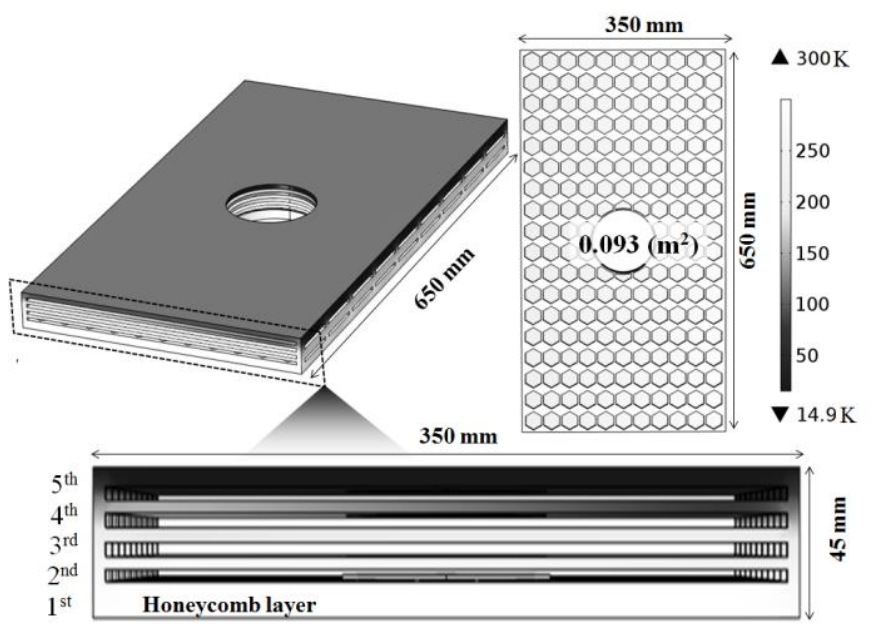

Fig. 4. Heat distribution of the zigzag-honeycomb type coil supporter. The first layer adopts honeycomb type. And the material of the supporter is fibrereinforced plastic.

TABLE I

HEAT BudGetS OF THE12 MW HTS GENERATOR MOdULE

\begin{tabular}{lll}
\hline \hline \multirow{2}{*}{ Heat source } & \multicolumn{1}{c}{ Components } & Heat load \\
\hline Excitation & Brushless HTS flux pump exciter & $10.2 \mathrm{~W}$ \\
Conduction & All components excluding the exciter & $5.5 \mathrm{~W}$ \\
Radiation & All components excluding the exciter & $3.9 \mathrm{~W}$ \\
Total heat load & Excitation \& Conduction \& Radiation & $19.6 \mathrm{~W}$ \\
\hline
\end{tabular}

(a) Connection point of the cold heat of the cryocooler

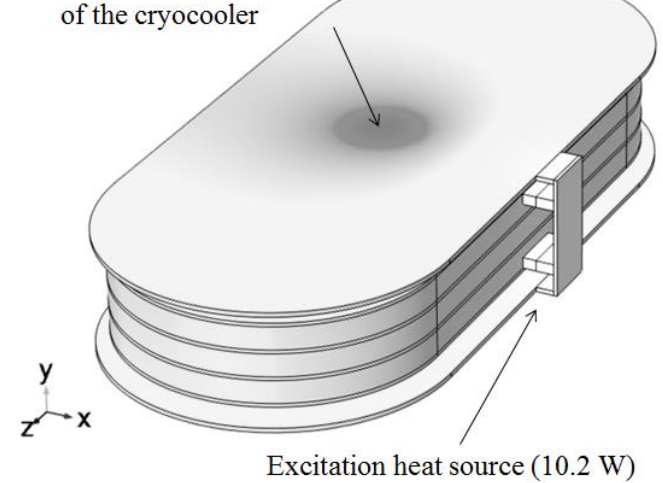

$\boldsymbol{\Delta} 16.1 \mathrm{~K}$
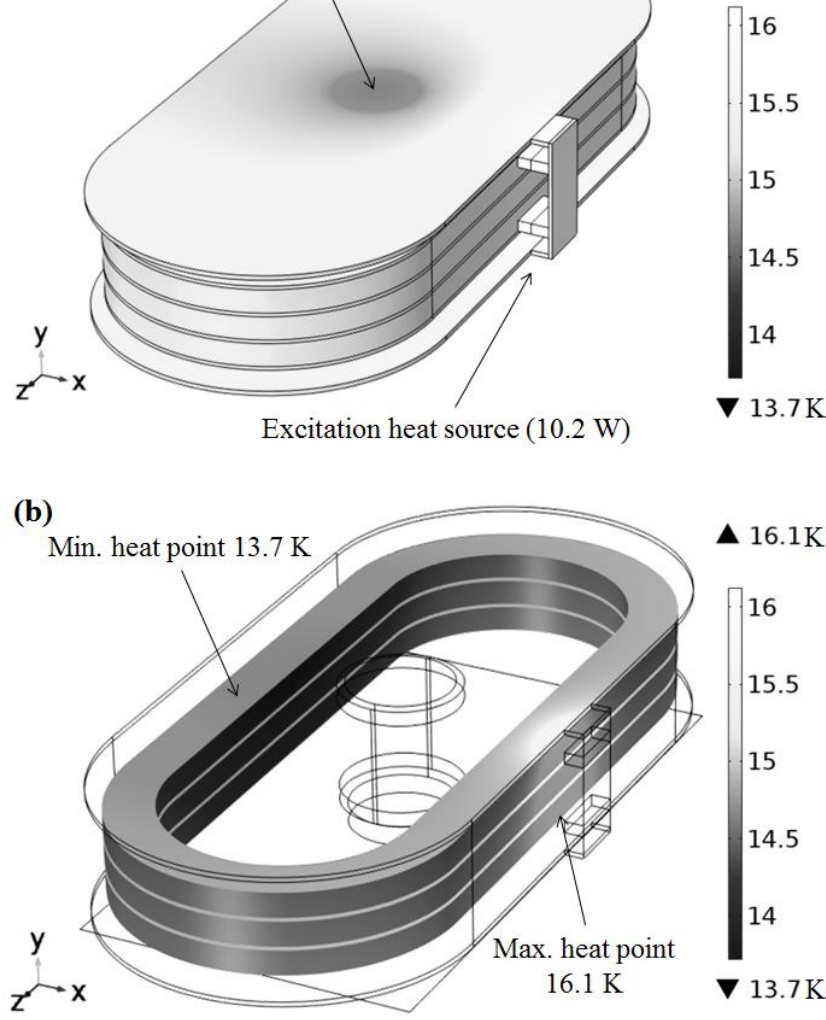

Fig. 5. (a) Heat distribution of the coil bobbin structures with HTS coils. (b) Heat distribution of the HTS coils. The lowest temperature of the coils is $13.7 \mathrm{~K}$, and the highest temperature of the coils is $16.1 \mathrm{~K}$. 